\title{
Inspiration of Gordon Music Teaching Theory on China's Current Music Education
}

\author{
Enzhe Guo \\ Department of Art, Hetao College, Bayannaoer, 015000, China
}

Keywords: Gordon music, teaching theory, music education

\begin{abstract}
Gordon is a well-known American music educator and psychologist, and is a music master who enjoys equal popularity with Orff, Kodaly, Dalcroze and Suzuki, and has great impacts on international music education field. Based on this, this paper discusses about the inspiration of Gordon music teaching theory on China's current music education.
\end{abstract}

\section{Introduction}

Edwin E. Gordon (1927-) is a well-known American contemporary music psychologist and music educator. Gordon establishes unique "music learning theory" from the perspective of students' individual needs, and thus this theory is widely concerned by music education circle. He is seen as a music education master who enjoys equal popularity with Kodaly, Orff, Dalcroze and Suzuki et al, and has important impacts on contemporary America and even the world. Gordon has important inspiration on and contribution to current and future music education, and Gordon music education plays a huge role in learning concepts of music teaching and theoretical research practice. Research in Gordon music theory has unique perspectives, and is featured by open course system, orderly teaching process, scientific research method and rigorous logical reasoning etc. Although this music theory has deficiencies, it has many aspects that worth learning and reference for China's current researches on music education.

\section{Core of Gordon music teaching research}

Music listening and thinking represent people's unique understanding of music learning process, and are also main ideas of Gordon music teaching research. Gordon's music life is distinct from many music educators in history, as he receives unique systematic academic research and rigorous training and he has been learning from folk music masters since about ten years old. Under the education and influence of music masters, Gordon has different music thoughts from others.

The former makes Gordon use normative and scientific methods for research on music education practice, while the latter makes Gordon find unique perspectives that are suitable for music practice when viewing music with special experience. With unique education experience, he has different views "listening and thinking" from others. Gordon wrote words "listening and thinking" in vocabulary of music education in 1975, and these words were results of people's long-term accumulation and continuous promotion of music teaching activities. As Gordon has mentioned in the concept of music listening and thinking, the relationship between music and listening \& thinking is just the same with that between language and thinking. This is closely related to Gordon's familiarity and application of understanding the learning of human language, and the entire activity of music learning can be summarized as words "listening and thinking". There are both relations and differences between listening \& thinking theory and theoretical concepts of music memorizing, perception and imitation. The critical condition of music learning is listening and thinking, which are the basis of musicality and are essential paths of target education. Complex and diverse listening and thinking growth can be divided into 8 types (without a certain order) and 6 stages (with a certain order), and forms a systematic music listening and thinking theoretical system and becomes the core of research on Gordon music teaching. 


\section{Inspiration of Gordon on China's current music education}

\section{(1) Strengthen research on music education and accept psychological results}

Chinese psychological music thought has several thousand years of development since the Spring and Autumn Period, and has undergone three processes namely incubation, inheritance and transition. At the incubation period, the thought of psychological music began to occur in various aesthetics, philosophy, musicology, ethics and histology fragmentarily and marginally. Lots of theories with value in use were people's description of psychological activities of music and research on psychological principles. Years from 1900 to 1950 were inheritance period, during which music educators began to study on psychological principles of music education, and research results of western psychology were gradually introduced to China, and research on issues related to music psychology began. Inheritance period belonged to Chinese psychological research at the initial state, "although learning was not intensive and some understanding was superficial, it still played a guiding and realizing role in today's research and was a forerunner”. Years from 1950 to 1999 were transition and growth period of Chinese psychology, especially in the late 1980s, during which research on music psychology reached climax and developed rapidly with widespread domestic publicity and influence of western psychology and reached unprecedented active state. This discipline had gradually clear research object and methods, and no longer relied on other disciplines, and had expanding research scope, generated a number of translations, monographs and academic papers, and stabilized its foundation. Psychology was separated from philosophy, and became an emerging discipline. It was an independent discipline with scientific research methods, and was not only a guarantee of successful research on music psychology but also a condition of the growth of music psychology. The uppermost contribution of psychological research results was the application in music education field, namely supplying the most scientific methods for research on music education. Foreign music education applied survey, experiment and test methods for research substantially, and attached special importance to experiments to testify researches. Data obtained by studying on samples gained by scientific sampling reflected detailed academic issues in theories and practice of music. Thus, research results were scientific and reliable. Research results expressed in music education were fully indicated. During graduate study, Gordon was very interested in psychology and thus had serious and in-depth study on psychology. When obtaining a doctor's degree, he also learned courses such as statistics, developmental psychology, evaluation field, educational measurement, and pedagogy etc related to psychology. These courses laid a very good professional foundation, and played an important role in education psychology theory that he researched. In the early 1970s, Gordon began to explore music learning theory and formulation of standard measurement musicality etc. The abovementioned researches were based on a large amount of researches on student samples of different grades. For example, his research on the growth of children's musicality involved nearly ten thousand sample children, and conclusions were reached over 5 years from 1974 to 1978. In review of this paper, the Greece, UK, Taiwan and the United States etc demonstrated such results through a large amount of researches after promotion of Gordon's learning theory and publication of musicality testing tool. It was noteworthy that Gordon had once compared musicality of peers in private schools and children aged between 5 and 8 in community music schools, supported his theory of musicality development period, and testified correctness of theory with scientific data.

\section{(2) Introduce foreign educational theories and explore Chinese music teaching methods enthusiastically}

Since the development from 1980s, Chinese music has introduced foreign music teaching methods nearly 30 years ago. But, Chinese music teaching methods have always remained at the stage of school songs. Thus, so far, Chinese music pedagogy has not good researches and improvement in terms of theory and practice. Most of China's music teaching theories are restricted by teaching methods of Kodaly, Dalcroze and Orff, and are also music teaching methods that are introduced and spread at the earliest with insignificant vigor and topics supported by the 
government. Some researches explain and elaborate topics such as perception, inspiration and application etc in one or more materials, but mostly have insufficient research experiment in lesson design and practical topic application and serious lack of personal views. For music teachers in middle and primary schools, courses involved in teaching methods of Kodaly, Dalcroze and Orff in practice are those to be learned in colleges, and are restricted in theories, so that students have no chance to have in-depth and systematic learning and thus could not achieve good application of teaching methods in classroom practice. From current actual situation, foreign music teaching methods cannot be fully introduced to China's basic education classroom. Based on China's national situation, there is not meticulous promotion. During learning of foreign advanced teaching models and teaching methods, backward comprehensive ability is the main problem in music education at current stage. Another important problem is that China's local music teaching methods are not really revealed from both national policies and individuals besides school songs during Chinese historical development, which is an in-depth problem worth deep thought and is very regretful. However, throughout the growth course of American education, foreign excellent educational concepts and models are basic paths of absorbing foreign cultures. Meanwhile, local cultural heritage shall be developed and inherited with mutual benefits and integration, so as to generate independent and vital results. Gaoqiu Baozhi's "we understand new music education from a global perspective" has just mentioned the key, namely find various problems in music by referring to the essence of each field and observe music from a unique perspective while further seeking teaching methods integrated with local characteristics, which are development goals of subsequent efforts of music teaching.

\section{(3) The importance of learning music ontology}

Previously, a lot of deficiencies and problems can be seen from the "Sixth National Quality Music Course Appraisal Site” which represents China’s highest level, such as "how to apply and concern about music ontology, why students are shy in classroom teaching, why not conduct cognitive rules from the positive music teaching, and how to conduct scientific education for music knowledge reasonably" etc. Experts point out a further research problem, "upon completion of modification required in new curriculum standard, understanding music notation shall be completed in primary schools, perception of general rules of the most basic structure of music such as period and comma, breathing and music shall be understood during high grades in primary schools and middle schools, and there would be problems in music learning in colleges if pitch, Curwen Gestures, roll-call, articulation mark, graphic notation and connection are not learned or concerned at low grades in primary schools, thus, we shall face ontology and conduct correct, sufficient and thriving teaching ", and focus on music educational methods which play a great role internationally. Music educational methods are established based on music ontology teaching. Body rhythm invented by Dalcroze is based on the understanding of all musical elements, and takes understanding of musical connotation and experiencing musical emotions as key points of education. During music education, Orff invented an instrument specialized for training of children's performance according to nursery rhymes, and thus realized educational objectives of a sense of rhythm and hip hop according to notation. Kodaly conducted teaching training method of first tone and rhythm roll-call by Curwen Gestures teaching method.

The importance of learning the music ontology is profound understanding of theoretical learning of Gordon music. Gordon's teaching theory has basic music skill and music content learning sequence. The so-called music skill refers to a type of skills consisting of creation, writing, performance, impromptu singing and performance, and singing by listening to and identifying notation. During learning, all vocabulary related to music shall be applied skillfully. To learn, know and apply music content effectively, we shall have at least one type of skills, otherwise, it is impossible to learn skills without lack of music content. So, Gordon classroom teaching has specialized training for tone and rhythm for the first ten minutes of each class. Thus, it can be seen that Gordon attaches great importance to teaching of rhythm and tone. "Music skill performance, writing, creation, singing by listening to and identifying notation, and impromptu singing are means 
and tools of conveying music aesthetics, and can be known and applied by great efforts and practice, and are practice road to aesthetic realm.” Thus, in music education, training techniques and skills and learning basic knowledge are the foundation of music learning. As famous American musician Manhattan Ville has said in music education design course plan, students' position and level of participation in music are the level of realizing music's artistic value for students, and music courses have long been not simple music classes with the progress of the times and have many rich and wonderful content, and practical experience and beauty of music can be obtained in practice of various music. Without the bridge of necessary knowledge and tool of skills, practice of music will be hindered, let alone aesthetics of music, creation of music and lifelong enjoyment of the fun of music.

\section{Conclusions}

During contemporary world educational practice, Gordon's teaching theory plays an inspiring and guiding role in China's music teaching theory, and has contribution of direct influence on music education history. It shall be noted that it is impractical to blindly conduct "copinism" in current education context. Thus, we shall have practical exploration constantly based on in-depth and comprehensive learning of Gordon's music theory, analyze limitations and applicability of China's music practice process, create music teaching constantly, and thus achieve the objective of enriching China's music teaching.

\section{References}

[1] Thomas Christensen, Ren Damin. "The Cambridge History of Western Music Theory" Introduction (Extract) [J]. Journal of Xinghai Conservatory of Music, 2011, (04).

[2] Chen Ping, Zhang Jianhua, Yan Xiaoyu, Han Han. Promote Teaching Quality Engineering and Enhance Overall Qualities of Students in Music Academies [J]. Journal of Xinghai Conservatory of Music, 2011, (04).

[3] KARMA,K.The ability to structure acoustic material as ameasure aptitude:summary and conclusions.. university of helsinki,institute of edu-cation researchbulletin 52 . 1980

[4] Wu Yong. Perfect Humanity and Beautify Course of Life-On Music Quality Courses for Non-music Majors [J]. Journal of Keshan Teachers College, 2004, (04).

[5] Song Bei. The Survey of the Methods of Music Psychology Research Based on the $3^{\text {rd }}$ National Research Conference on Music Psychology [J]. People’s Music. 2010 (01) 